http://https://ejournal.iai-tribakti.ac.id/index.php/perbankan

\title{
Etika Bisnis Islam Dalam Transaksi Jual Beli di Pasar Tradisional Ngronggo Kota Kediri
}

\section{Islamic Business Ethics In Buying and Selling Transactions at Ngronggo Traditional Market Kediri City}

\author{
Ihna Nilava ${ }^{1}$, Ahmad Fauzi ${ }^{2}$ \\ ${ }^{1}$ Institut Agama Islam Tribakti Kediri, ${ }^{2}$ Institut Agama Islam Tribakti Kediri \\ ${ }^{1}$ Ihna.nilava@gmail.com, ${ }^{2}$ ahmadfauzi007@gmail.com
}

\begin{abstract}
Buying and selling activities are the activity of exchanging goods or material ownership permanently. One of the places for buying and selling is the Market. Along with the times of very rapid economic development, business competition is increasingly high. With very high competitors, business people use various methods to get high profits, so business people often ignore Islamic business ethics in running their business. Ethics is a good behavior of human behavior that covers social values. Good ethics includes honesty, reliability, disciplined loyalty. This study analyzes more deeply about Islamic business ethics using qualitative descriptive methods because the data used are through observation, interviews and documentation. In this context the researcher wants to examine the application of Islamic business ethics in the sale and purchase transactions at the Ngronggo Traditional Market in Kediri City. The results of the study of the application of Islamic business ethics in the sale and purchase transactions at the Ngronggo Market in Kediri City, led most of the traders to implement and run Islamic business ethics. although not all traders have adopted Islamic business ethics.
\end{abstract}

Keywords: Islamic Business Ethics, Buying and Selling, Traditional Markets

\begin{abstract}
Abstrak
Kegiatan jual beli merupakan kegiatan tukar menukar barang atau materi kepemilikan secara permanen. Salah satu tempat kegiatan jual beli adalah Pasar.Seiring perkembangan zaman perkembangan ekonomi yang sangat pesat menimbulkan persaingan bisnis yang semakin tinggi. Dengan pesaing yang sangat tinggi pelaku bisnis menggunakan berbagai cara untuk
\end{abstract}




\section{Ihna Nilava, Ahmad Fauzi| Etika Bisnis Islam...}

mendapatkan keuntungan yang tinggi sehingga pelaku bisnis sering mengabaikan etika bisnis Islam dalam menjalankan bisnisnya. Etika merupakan perilaku baik buruknya tingkah laku manusia yang mencangkup nilai nilai sosial. Etika yang baik mencangkup honesty, Reability, Loyalitas Disiplin. Penelitian ini menganalisis lebih dalam mengenai etika bisnis Islam dengan menggunakan metode deskriptif kualitatif karena data yang digunakan melalui observasi, wawancara dan dokumentasi. Dalam konteks ini peneliti ingin mengkaji tentang penerapan etika bisnis Islam dalam transaksi jual beli di Pasar Tradisional Ngronggo Kota Kediri. Hasil penelitian penerapan etika bisnis Islam dalam Transaksi jual beli di Pasar Ngronggo Kota Kediri bawasanya sebagian besar pedagang sudah menerapkan dan menjalankan etika bisnis Islam. meskipun belum semua pedagang yang sudah menerapkan etika bisnis Islam.

Kata Kunci: Etika Bisnis Islam, Jual Beli, Pasar Tradisional

\section{Pendahuluan}

kegiatan jual beli merupakan kegiatan tukar menukar barang atau materi kepemilikan secara permanen. Salah satu tempat kegiatan jual beli adalah Pasar.Seiring perkembangan zaman perkembangan ekonomi yang sangat pesat menimbulkan persaingan bisnis yang semakin tinggi. Dengan pesaing yang sangat tinggi pelaku bisnis menggunakan berbagai cara untuk mendapatkan keuntungan yang tinggi sehingga pelaku bisnis sering mengabaikan etika bisnis Islam dalam menjalankan bisnisnya. Seperti contoh masih banyak para pedagang yang belum menerapkan etika bisnis Islam seperti halnya berperilaku tidak jujur, pengurangan takaran atau timbangan, pengoplosan barang bagus dengan barang buruk dan lain sebagainya yang terjadi di pasar Tradisional. ${ }^{1}$

${ }^{1}$ Umi Mursidah," Penerapan Etika Bisnis Islam Dalam Transaksi Jual Beli di Pasar Tradisional", (Skripsi, Universitas Islam Negri Raden Intan 2017), h. 20. 
Hal tersebut yang mengakibatkan cara calon pembeli merasa tidak nyaman untuk datang ke pasar tradisional. Pembeli atau konsumen seharusnya menerima barang dalam kondisi baik dan dengan harga yang wajar, mereka juga harus diberitahu apabila terdapat kekurangan-kekurangan pada suatu barang yang dijual sehingga si pembeli bisa membedakan mana barang bagus dan tidak. ${ }^{2}$

Kelengkapan suatu informasi itu sangat penting untuk mengetahui kelebihan dan kekurangan suatu barang dan produk. Untuk menjadi faktor penentuan bagi pembeli agar bisa menentukan pilihanya, oleh karena itu informasi merupakan hal pokok yang dibutuhkan setiap konsumen.

Perilaku jujur dalam memberikan suatu informasi sangat diperlukan oleh konsumen. Karena kejujuran yang di praktikan para nabi dan rasul adalah seorang pedagang yang terkenal dengan kejujuranya. Dalam Al-Qur'an surat Asy'ara ayat $181-183$ :

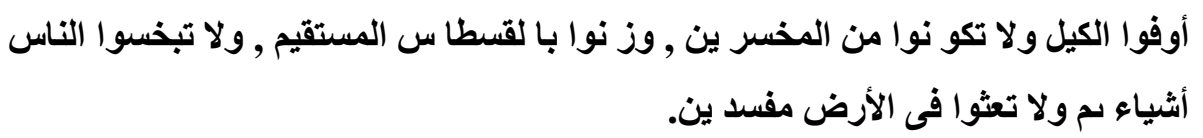

Terjemahnya : Sempurnakanlah takaran dan janganlah kamu termasuk orang - orang yang merugikan, dan timbangkanglah yang lurus, dan Janganlah kamu merugikan manusia padahakhaknya dan janganlah kamu merajalela dimuka bumi dengan membuat kerusakan ".3

${ }^{2}$ Ema Mardiyah, Asep Suryanto,"Analisis Penerapan Etika Bisnis Syariah di Pasar Tradisional Singaparna", (Skripsi, Fakultas Ekonomi Universitas Tasikmalaya, 2010), h. 2. h. 374 .

${ }^{3}$ Departemen Agama RI, Al-Qur'an dan Terjemahnya, (Bandung : Diponegoro, 2011), 


\section{Ihna Nilava, Ahmad Fauzi| Etika Bisnis Islam...}

Maksud dari ayat diatas adalah Allah SWT menganjurkan kepada seluruh umatnya khususnya untuk berperilaku jujur dalam menjalankan bisnisnya dalam bentuk apapun. ${ }^{4}$

Menurut Briffin dan Ebert bisnis adalah (perdagangan) dalam arti luas adalah sesuatu menggambarkan aktivitas dan institusi yang memproduksi barang dan jasa dalam kehidupan sehari- hari. Bisnis merupakan suatu organisasi yang menyediakan barang dan jasa yang bertujuan untuk mendapatkan keuntungan. Namun disamping tujuan tersebut, hakikat dari kegiatan bisnis itu adalah untuk memenuhi kebutuhan sebagai makhluk sosial. ${ }^{5}$

Dari teori diatas, peneliti akan mengambil penelitian yang ada di Pasar ngronggo yang ada di Kec. Ngronggo Kota Kediri Jawa Timur 64129. Penelitian ini menarik karena peneliti melihat adanya perilaku menyimpang pedagang yang belum sesuai dengan apa yang diterapkan di etika bisnis Islam. Selain itu juga masalah yang dilihat peneliti tidak semua pedagang di pasar ngronggo di bolehkan masuk berjualan di pasar tersebut, masih banyak pedagang yang bergadang di luar lingkungan pasar ngronggo dan masih banyak juga buah dan sayuran yang menimbun dipasaar tersebut, dilihat dari permasalahan - permasalahan yang ada peneliti menarik untuk meneliti di pasar grosir ngronggo Kediri. ${ }^{6}$

Berdasarkan pengamatan peneliti, permasalahan disini timbul ketika banyaknya transaksi jual beli buah buahan dan sayuran seperti: buah naga, nanas, mangga, rambutan, semangka, pisang, sirsak dan buah lainya, adapun

${ }^{4}$ Johan Arifin, Etika Bisnis Islami, (Semarang : Walisongo Press, 2013), h. 154.

5 Muhammad Farid Amilatuz Zahro,"Analisis Penerapan Etika Bisnis Islam Dalam Perdagangan Sapi di Pasar Hewan Pasirian", Jurnal Iqtishoduna, Vol.6, 2 (Oktober, 2015), h. 13.

\footnotetext{
${ }^{6}$ Hasil pengamatan langsung (observasi), pada tanggal, 7 januari 2020.
} 
sayur sayuran yang ada dipasar ngronggo masih belum diketahui apakah dalam transaksi sehari-hari pedagang di pasar ngronggo sudah benar-benar menerapkan aturan etika bisnis Islam. Dan masyarakat umum yang ilmu pengetahuan kurang mengetahui tentang etika bisnis islami belum tentu tidak sesuai dalam praktek jual belinya.

\section{Metode}

Jenis penelitian yang dilakukan penulis adalah lapangan, yaitu penelitian langsung berhubungan dengan obyek yang diteliti. Metode yang digunakan dalam penelitian ini adalah metode deskriptif kualitatif karena data yang digunakan melalui observasi, wawancara dan dokumentasi. Dalam konteks ini peneliti ingin mengkaji tentang penerapan etika bisnis Islam dalam transaksi jual beli buah dan sayuran di Pasar Tradisional Ngronggo Kota Kediri.

\section{Pembahasan}

\section{Etika Bisnis}

Mendalami etika berasal dari bahasa yunani ethos yang berarti kebiasaan atau karakter. ${ }^{7}$ Etika merupakan perilaku baik buruknya tingkah laku manusia yang mencangkup nilai nilai sosial. Etika yang baik mencangkup honesty, Reability, Loyalitas Disiplin.

Dari uraian di atas dapat disimpulkan bahwa Etika bisnis merupakan norma-norma etika yang dilandaskan pada Al-Qur'an dan Hadits yang dijadikan pedoman oleh siapapun hendak melakukan bisnis.Yang didalamnya terdapat prinsip-prinsip moralitas. . Etika merupakan studi sistematika tentang tabiat konsep nilai, baik buruk ,harus, benar, salah dan lain sebagainya dan prinsip-prinsip umum yang membenarkan kita untuk mengaplikasikannya atas

\footnotetext{
${ }^{7}$ Faisal Badroen, Etika Bisnis Islam, (Jakarta : Prenada Media Group, 2006), h. 5.
} 


\section{Ihna Nilava, Ahmad Fauzi| Etika Bisnis Islam...}

apa saja. ${ }^{8}$ Etika merupakan baik berhubungan dengan diri sendiri ataupun orang lain. ${ }^{9}$

Untuk menilai perilaku baik buruknya perbuatan bisa diperhatikan kriterianya seperti halnya firman Allah Al -Qur'an Surat Al - Baqarah ayat 263 sebagai berikut:

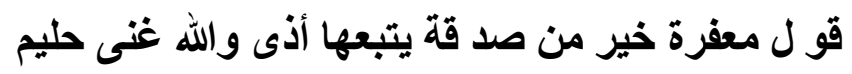

Terjemahnya : "Perkataan yang baik dan pemberian maaf lebih baik dari sedekah yang diiringi sesuatu yang menyakitkan (perasaan si penerima), Allah maha kaya lagi maha penyantun. ${ }^{10}$

Etika bisnis dalam Islam merupakan sejumlah perilaku etis bisnis (akhlaq al Islamiyah) yang dibungkus dengan nilai-nilai syariah yang mengedepankan halal dan haram. Jadi perilaku yang etis itu ialah perilaku yang mengikuti perintah Allah dan menjauhi laranganya. Dalam islam etika bisnis ini sudah banyak dibahas dalam berbagai literatur dan sumber utamanya adalah Al-Qur'an dan sunnaturrasul. Pelaku-pelaku bisnis diharapkan bertindak secara etis dalam berbagai aktivitasnya.Kepercayaan ,keadilan dan kejujuran adalah elemen pokok dalam mencapai suksesnya suatu bisnis dikemudian hari. ${ }^{11}$

Landasan yang digunakan oleh Etika berbisnis yaitu berdasarkan AlQuran dan Hadits. Pada awalnya etika berbisnis dalam islam telah ditetapkan dalam Al-Qur'an, secara etik berekonomi telah ditetapkan dalam islam seperti

\footnotetext{
${ }^{8}$ Muhammad Saifullah,"Etika Bisnis Islami Dalam Praktek Bisnis Rasulullah", journal eEtika Bisnis Islam, Vol. 19, 1 (Mei 2011), h. 50.

${ }^{9}$ Buchari Alma, Donni Juni Priansa, Manajemen Bisnis Syariah, h. 376. 2011)

${ }^{10}$ Departemen Agama RI, Al- Qur'an dan Terjemahnya, (Bandung : Diponegoro,

${ }^{11}$ Fitri Amalia, "Etika Bisnis Islam: konsep Dan Implementasi Pada Pelaku Usaha kecil", h. 118.
} 
halnya dalam bidang produksi, konsumsi, distribusi dll yang berkaitan dengan ekonomi telah diatur berdasarkan etika-etika Islam.

Adapun bisnis Islam mengenai etika bisnis terdapat dalam ayat-ayat Al-Qur'an, Surat asy-syura ayat 181-184 :

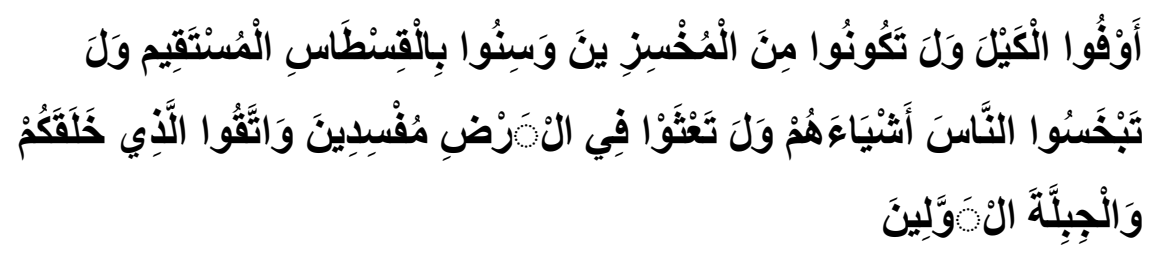

Terjemahnya : "Sempurnakanlah takaran dan janganlah kalian termasuk orang-orang yang merugikan; dan timbanglah dengan timbangan yang lurus. Dan janganlah kalian merugikan manusia pada hak-haknya dan janganlah kalian merajalela di mukabumi dengan membuat kerusakan; dan bertakwalah kepada Allah yang telah menciptakan kalian dan umat-umat yang dahulu”.(Q.S. asy-syura ayat 181-184). ${ }^{12}$

\section{Bentuk Transaksi Bisnis di Pasar grosir Ngronggo Kota Kediri}

Pasar Ngronggo merupakan pasar tradisional yang berada di Kecamatan Ngronggo Kota Kediri, pasar tersebut dikelola oleh UPTD pasar Kota Kediri Jawa Timur yang diketahui oleh Bapak Syaiul Fuad selaku Ketua Pasar. Selain itu Pasar Ngronggo adalah salah satu tempat pusatnya bahan pangan seperti buah dan sayuran. Pasar Ngronggo sangat diminati penduduk sekitar dikarenakan harganya terjangkau, dan masih menjadi interaksi yang kuat dalam masyarakat dan mekanisme transaksinya menggunakan metode tawar menawar. Kelebihan lainya adalah bisa melihat dan memastikan langsung barang yang umumnya masih baru dan segar.

Bentuk transaksi penjualan dipasar grosir Kediri adalah menggunakan sistem cash (tunai), ada juga yang membayar menggunakan tukar menukar

\footnotetext{
${ }^{12}$ Al-Qur'an, 26: 181-184.
} 


\section{Ihna Nilava, Ahmad Fauzi| Etika Bisnis Islam...}

(barter) barang dengan para pedagang. Tetapi karena di kacamatan Ngronggo mayoritas masyarakatnya bermata pencaharian sebagai pedagang sayuran dan buah, mereka saling melakukan barter barang dengan barang dengan para pedagang. Misalnya penjual memiliki sayuran seperti terong, nantinya ditimbang dan ditukar dengan kubis atau sayuran lainya.

Dari hasil Observasi yang peneliti peroleh ada beberapa pedagang yaitu yang pertama mengenai cara pedagang menawarkan daganganya kepada pembeli yaitu dengan berbagai cara diantaranya mengobral barang daganganya kepada pembeli yang lewat didepan kiosnya dan ada juga yang memuji barang daganganya.

Pada teori ini melihat kewajiban yang dilakukan pada seseorang pedagang, dimana kewajiban itu layak untuk dilakukan sebagai tanggungjawab yang seharusnya dilakukan oleh pedagang pada umumnya. Misalkan memberikan pelayanan yang baik kepada semua pembeli dengan barang dan jasa yang bermutu dan sebanding dengan harga. Hal ini telah dilakukan oleh Bapak Budi, Bapak Fuad, Ibu Erna, Ibu Simpen. ${ }^{13}$

Hasil observasi lapangan mengenai perdagangan dipasar ngronggo peneliti meneliti barang barang yang dijual dipasar seperti para pedagang buah dan sayuran sayuran penjual menjual barang yang masih seger atau gk ada kecacatan pada barang. Pembelian di pasar grosir masih ditentukan pada penjualnya minimal pembelian $5 \mathrm{~kg}$. Jika ada pembeli yang membeli kurang lebih $5 \mathrm{~kg}$ biasanya tidak diperbolehkan untuk membeli justru dikasih sama penjual, dipasar grosir tidak menjual eceran dikarenakan semakin pembeli membeli barang lebih banyak semakin murah harga yang dijual. Oleh karena itu pembeli merasa senang dan penjual juga merasa senang. Hal itu terjadi pada pedagang buah seperti Ibu erni.

${ }^{13}$ Observasi, Pada Tanggal 28 Januari sampai 1 Februari 2020 


\section{Etika Bisnis di Pasar grosir Ngronggo Kota Kediri}

\section{Etika dengan pelaku bisnis}

Seorang penjual buah didalam pasar grosir Kediri namun belum termasuk pegadang tetep atau belum mempunyai kios penjual yang peneliti temui bernama bapak Budi yang sudah berjualan selama 5 tahun. Beliau mulai merintis usahanya pada tahun 2015 lokasi penjualan tidak tetap masih pindah pindah. Bapak Budi memutuskan berjualan mempunya kelebihan keahlian berjualan. Modal awal 3.000.000,00 untuk belanja buah di petani. Keuntungan rata rata bapak Budi terima naik turun dari kondisi pasar yang sedang rame ataupun sepi serta pembeli yang ada dipasar grosir Ngronggo. Untuk pesaingan pedagang lainya, bapak Budi menuturkan bahwa persaingan di pasar grosir ini semua pedagang berteman dengan baik dan melakukan kompetisi yang sangat sehat dan tidak menjelek jelekan antara pedagang satu dang pedagang lainya. ${ }^{14}$

Hasil wawancara dengan ibu simpen seorang pedagang sayuran. Dari bendo sari krass. Ibu Simpen berjualan dipasar grosir Kediri sudah 10 tahun yang lalu beliau berjualan sayuran di pasar grosir Kediri sudah termasuk pedagang tetap karena sudah memiliki kios dan kartu tanda pedagang. Pengambilan barang sayuran melalui bakul bakul atau sawah milik petani lain. Pembelian tidak dilakukan untuk eceran, minimal pembelian $1 \mathrm{sak} / 30 \mathrm{~kg}$ minimal pembeli sayuran dipasar grosir Kediri. Harga satu 1 sak bisa dijual seharga Rp. 97.000,00 harga lebih murah. Barang yang tidak habis tidak untuk ditimbun malah sebaliknya dijual lagi untuk esok harinya. Barang yang busuk tidak untuk dijual malah diservice kembali / diganti baru sama petani. Satu hari ibu simpen dikirimi bakulnya 100 sak/hari. Dan ibu simpen juga sudah mempunyai langganan yang setiap harinya membeli sayuran dikiosnya, mengenai hubungan dengan pedagang lainya ibu Simpen tidak

\footnotetext{
${ }^{14}$ Budi, Pedagang, Wawancara, 1 februari 2020
} 


\section{Ihna Nilava, Ahmad Fauzi| Etika Bisnis Islam...}

menganggapnya sebagai saingan karena menurut beliau semua pedagang sama berjuang mencari nafkah dan mencyukupi kebutuhan sehari hari, jadi semua pedagang pasar berhubungan baik antara pedagang satu dengan pedagang lainya. Ujar ibu Simpen. ${ }^{15}$

\section{Etika melayani pembeli}

Kehiduan dikawasan pasar grosir Kediri sangat menjanjikan semua pedagang yang ada di pasar grosir Kederi harus mempunyai usaha dikawasan tersebut. Ibu Erna pedagang Jagung, yang sudah berjualan di pasar grosir Kediri selama 13 yaitu sejak 2007. " memang dilingkungan pasar harus sabar soalnya dipasar ini banyak sekali sainganya, namun setiap pedagang disini tidak sama dalam melayani dan memberikan harga yang berbeda beda kepada pembeli. Disini pedagang berusaha memberikan pelayanan yang baik kepada pembeli agar pembeli nyaman dalam melakukan transaksi jual beli di kios saya. boleh hanya mampir untuk melihat - lihat saja dulu siapa tau menarik untuk dibeli, jadi menurut saya usaha boleh sama tapi yang membedakan hanya pelayanan dan harga harganya" ujar ibu Erna.

\section{Etika Menawarkan barang - barang yang berkualitas}

Berdasarkan hasil wawancara yang penulis dapat selama penelitian di Pasar Ngronggo kota Kediri ada salah satu pedagang yang peneliti wawancara yaitu seorang pedagang sayuran seperti kangkung dan sayuran lainya. Beliau mulai merintis usaha berjualan di pasar grosir hampir 10 tahun. Mulai merintis usaha ini dari 2008 silam sampai sekarang. Bapak Budi memutuskan berjualan di pasar grosir karena dilihat dari pasar grosir pasti jg banyak peminat untuk membeli dipasar tersebut. Berjualan sayuran dengan cara memesan dengan barang dagangannya dengan petani. Sebelum diambil beliau memilah terlebih

${ }^{15}$ Simpen, Pedagang, Wawawncara, 1 februari 2020 
dahulu mana yang masih seger agar layak untuk dijual. Karena takutnya jika pembeli mengetahui ada barang yang cacat nantinya pembeli tersebut tidak mau lagi membeli dikios bapak budi. ${ }^{16}$

\section{Etika menentukan harga}

Hasil dari wawancara dengan ibu Ani, seorang pedagang sayuran seperti terong, kubis, wortel dan lainya. Ibu Ani bertempat tinggal di Tulung Agung jauh dari pasar dan harus menyita waktu cukup lama untuk nyampe di pasar grosir Kediri. Ibu Ani mulai berdagang sayuran baru 8 tahun, dan usia ibu Ani sendiri memasuki 40 tahun. Cara ibu Ani menentukan harga kepada pembelinya yaitu dengan cara melihat dulu gimana perkembangangan harga sayuran saat di dipetani agar bisa memberikan harga pas kepada pembelinya. ${ }^{17}$

Hasil wawancara dengan ibu simpen seorang pedagang sayuran. Dari bendo sari krass. Ibu Simpen berjualan dipasar grosir Kediri sudah 10 tahun yang lalu beliau berjualan sayuran di pasar grosir Kediri sudah termasuk pedagang tetap karena sudah memiliki kios dan kartu tanda pedagang. Pengambilan barang sayuran melalui bakul bakul atau sawah milik petani lain. Pembelian tidak dilakukan untuk eceran, minimal pembelian $1 \mathrm{sak} / 30 \mathrm{~kg}$ minimal pembeli sayuran dipasar grosir Kediri. Harga satu 1 sak bisa dijual seharga Rp. 97.000,00 harga lebih murah. Barang yang tidak habis tidak untuk ditimbun malah sebaliknya dijual lagi untuk esok harinya. Barang yang busuk tidak untuk dijual malah diservice kembali / diganti baru sama petani. Satu hari ibu simpen dikirimi bakulnya 100 sak/hari. Dan ibu simpen juga sudah mempunyai langganan yang setiap harinya membeli sayuran dikiosnya, mengenai hubungan dengan pedagang lainya ibu Simpen tidak menganggapnya sebagai saingan karena menurut beliau semua pedagang sama

\footnotetext{
${ }^{16}$ Budi, Pedagang, Wawancara, 1 februari 2020

${ }^{17}$ Ani, Pedagang, Wawancara, 1 Februari 2020
} 


\section{Ihna Nilava, Ahmad Fauzi| Etika Bisnis Islam...}

berjuang mencari nafkah dan mencyukupi kebutuhan sehari hari, jadi semua pedagang pasar berhubungan baik antara pedagang satu dengan pedagang lainya. Ujar ibu Simpen. ${ }^{18}$

Ibu Sunita adalah salah satu pelanggan setia di pasar grosir ngronggo, karena rumah beliau berada di desa Lirboyo. Jika masalah puas atau tidaknya belanja di pasar grosir, ibu Sunita merasa sangat puas karena dilihat dari segi pelayananya dan juga harga yang terjangkau sangat ekonomis untuk dijual lagi. Untuk pelayanan di pasar grosir ngronggo ramah - ramah dan pedagang sudah mengenal satu sama lain jadi untuk bertransaksi enak. Untuk masalah penerapan etika bisnisnya ada beberapa pedagang yang belum menerapkan sepenuhnya tentang etika bisnis, dan ada juga yang sudah menerapkan etika bisnisnya. Hanya saja sejauh ini sepengetahuan beliau banyak pedagang yang sudah menerapkan etika bisnis dalam melakukan transaksi penjualanya. ${ }^{19}$

Ibu yani merupakan seseorang yang sering berbelanja di pasar grosir Ngronggo karena pasar grosir tersebut dilihat dari harganya sangat ekonomis atau sangat murah untuk bisa dijual kembali dengan harga yang murah, dilihat dari pelayanannya juga sangat baik. Penerapan etika bisnis di pasar grosir ngronggo belum semua bakul atau pedagang yang sudah menerapkan etika bisnis, meskipun sudah banyak yang sudah menerapkan etika bisnis Islam. Menurut penilaian ibu yani tentang etika bisnis islam dengan cara melakukan transaksi dengan jujur, tanggung jawab, amanah, dan dapat dipercaya. Oleh karena itu hampir semua pedagang yang ada di pasar grosir ngronggo sudah menerapkan etika bisnis Islam. ${ }^{20}$

\section{Kesimpulan}

\footnotetext{
${ }^{18}$ Simpen, Pedagang, Wawawncara, 1 februari 2020

${ }^{19}$ Sunita, Pembeli, Wawancara, 3 Februari 2020.

${ }^{20}$ Yani, Pembeli, Wawancara, 3 Februari 2020.
} 
Hasil penelitian mengenai penerapan etika bisnis Islam dalam Transaksi jual beli di Pasar Ngronggo Kota Kediri bawasanya sebagian besar pedagang sudah menerapkan dan menjalankan etika bisnis Islam. meskipun belum semua pedagang yang sudah menerapkan etika bisnis Islam. Hasil dari wawancara yang peneliti dapat dari beberapa pedagang yang dijadikan sempel penelitian dapat diketahui pedagang di Pasar Ngronggo Kota Kediri bawasannya sebagian dari pedagang dipasar tersebut sudah menjalankan prinsip etika bisnis Islam seperti halnya jujur, tanggung jawab, amanah dan dapat dipercaya.

\section{Daftar Pustaka}

Alma, Buchari \& Donni Juni Priansa, Manajemen Bisnis Syariah, Bandung : Alfabeta CV, 2016.

Amalia, Fitri, Etika Bisnis Islam: konsep Dan Implementasi Pada Pelaku Usaha kecil" Jurnal Al Iqtishad Vol.6 No.1, Januari 2014.

Arifin, Johan, Etika Bisnis Islami, Semarang : Walisongo Press, 2013.

Badroen, Faisal, Etika Bisnis Islam, Jakarta : Prenada Media Group, 2006.

Departemen Agama RI, Al- Qur'an dan Terjemahnya, Bandung : Diponegoro, 2011.

Departemen Agama RI, Al-Qur'an dan Terjemahnya, Bandung : Diponegoro, 2011.

Mardiyah, Ema \& Asep Suryanto, Analisis Penerapan Etika Bisnis Syariah di Pasar Tradisional Singaparna, Skripsi, Fakultas Ekonomi Universitas Tasikmalaya, 2010.

Mursidah, Umi, Penerapan Etika Bisnis Islam Dalam Transaksi Jual Beli di Pasar Tradisional, Skripsi, Universitas Islam Negri Raden Intan 2017.

Saifullah, Muhammad, Etika Bisnis Islami Dalam Praktek Bisnis Rasulullah, 
Ihna Nilava, Ahmad Fauzi| Etika Bisnis Islam...

journal eEtika Bisnis Islam, Vol. 19 No. 1, Mei 2011.

Zahro, Muhammad Farid Amilatuz, Analisis Penerapan Etika Bisnis Islam Dalam Perdagangan Sapi di Pasar Hewan Pasirian, Jurnal Iqtishoduna, Vol.6, No.2, Oktober, 2015. 